\title{
Semeadura cruzada em cultivares de soja com tipo de crescimento determinado
}

\section{Sowing in crossed rows in soybean cultivars with determinate growth habit}

\author{
Alvadi Antonio Balbinot Junior ${ }^{1 *}$; Sergio de Oliveira Procópio ${ }^{2}$; \\ Henrique Debiasi ${ }^{1}$; Julio Cezar Franchini ${ }^{1}$; Fernando Panison ${ }^{3}$
}

\section{Resumo}

\begin{abstract}
Alterações no arranjo espacial de plantas podem aumentar a produtividade de grãos de soja sem aumentos expressivos no custo de produção. A técnica denominada "semeadura cruzada" vem despertando interesse no setor produtivo por ter sido utilizada por alguns recordistas de produtividade de soja no Brasil. O objetivo desse trabalho foi avaliar o desempenho agronômico de cultivares de soja com tipo de crescimento determinado, em diferentes arranjos de plantas. Os experimentos foram conduzidos em Londrina, PR, nas safras 2011/12 e 2012/13, sob o delineamento de blocos completos ao acaso, em esquema fatorial $2 \times 2 \times 2$, com três repetições. Os tratamentos foram formados pela combinação de dois espaçamentos entre fileiras $(0,4$ e $0,6 \mathrm{~m})$, duas densidades de semeadura (375.000 e 562.500 sementes ha $^{-1}$ ) e de dois sistemas de semeadura (semeadura cruzada e não cruzada). Na safra 2010/11, utilizou-se a cultivar BRS 294 RR e na safra 2011/12 a cultivar BRS 295 RR. Nas duas safras, a produtividade de grãos não foi influenciada pelo sistema de semeadura, pela densidade de plantas e pela interação entre esses fatores, o que demonstra a alta plasticidade fenotípica das cultivares utilizadas. Para a cultivar BRS 294 RR, o espaçamento de 0,6 m entre fileiras conferiu maior produtividade de grãos em relação ao espaçamento de $0,4 \mathrm{~m}$, principalmente porque proporcionou aumento da produção de grãos oriunda dos ramos.
\end{abstract}

Palavras-chave: Arranjo espacial de plantas, densidade de plantas, espaçamento entre as fileiras, Glycine $\max$

\begin{abstract}
Increases in the soybean grain yield without significant alterations in the production cost can be achieved with variations in the spatial plant arrangement. The sowing in crossed rows has aroused the interest of Brazilian soybean producers once this practice was used in some areas with record-breaking soybean yield in Brazil. This study aimed to evaluate the agronomic performance of soybean cultivars with determinate growth habit managed under different spatial plant arrangements, including crossed rows. The experiments were carried out in Londrina, PR, at 2011/12 and 2012/13 growing seasons. A randomized complete block experimental design in a $2 \times 2 \times 2$ factorial scheme was used, with three replications. The treatments were formed by combining two row spacing $(0.4$ and $0.6 \mathrm{~m})$, two seeding rates $\left(375,000\right.$ and 562,500 seeds ha $^{-1}$ ) and two sowing systems (crossed or parallel rows). The cultivar BRS 294 RR was used in 2011/12 and BRS 295 RR in 2012/13 growing season. In both cultivars and
\end{abstract}

1 Eng ${ }^{\text {os }}$ Agros, Drs., Empresa Brasileira de Pesquisa Agropecuária, EMBRAPA Soja, Londrina, PR. E-mail: alvadi.balbinot@ embrapa.br; henrique.debiasi@embrapa.br; julio.franchini@embrapa.br

2 Eng ${ }^{\circ}$ Agr $^{\circ}$, Dr., EMBRAPA Tabuleiros Costeiros, Aracajú, SE. E-mail: sergio.procopio@embrapa.br

3 Eng $^{\circ}$ Agr $^{\circ}$, Discente do Curso de Doutorado em Produção Vegetal, Universidade do Estado de Santa Catarina, UDESC, Lages, SC.E-mail: fernandopanison@ hotmail.com

* Autor para correspondência 
years the grain yield was not affected by the sowing system, seeding rate, or by the interactions among factors, showing the high soybean phenotypic plasticity. Row spacing of $0.6 \mathrm{~m}$ showed the highest soybean grain yield in BRS 294 RR, mainly due to a higher grain production in the branches.

Key words: Spatial plant arrangement, plant density, row spacing, Glycine max

\section{Introdução}

O aumento da produtividade de grãos na cultura da soja pode ser alcançado pelo melhoramento genético e pelo aprimoramento no manejo do solo e da cultura. Dentre as práticas de manejo, o arranjo espacial das plantas pode afetar expressivamente a velocidade de fechamento das entre linhas (SHAW; WEBER, 1967; HEIFFIG et al., 2006), a produção de massa seca (COX; CHERNEY, 2011), a arquitetura das plantas (COX; CHERNEY; SHIELDS, 2010), a severidade de doenças (LIMA et al., 2012) e a produtividade de grãos da cultura (BRUIN; PEDERSEN, 2008; HANNA et al., 2008; RAMBO et al., 2003, 2004). Isso ocorre porque o arranjo de plantas influencia na competição intraespecífica e, consequentemente, na quantidade de recursos do ambiente - água, luz e nutrientes - disponíveis para cada planta.

O arranjo espacial pode ser alterado pela densidade de plantas e pelo espaçamento entre as fileiras. Vários trabalhos têm demonstrado a baixa resposta da cultura da soja às variações de densidade de plantas (PIRES; COSTA; THOMAS, 1998; HEIFFIG et al., 2006). Esse resultado é função da alta plasticidade fenotípica da soja, a qual é definida como a capacidade da planta alterar sua morfologia e componentes de rendimento a fim de adequá-los às condições impostas pelo arranjo espacial dos indivíduos (COOPERATIVE EXTENSION SERVICE AMES, 1994). Ou seja, em baixa densidade, as plantas de soja tendem a emitir maior quantidade de ramos, aumentando o número de vagens por planta, compensando a menor quantidade de indivíduos por área pela maior produção por planta. No entanto, em algumas cultivares e ambientes, a densidade pode afetar a produtividade (TOURINO; REZENDE;
SALVADOR, 2002; COX; CHERNEY, 2011). Em relação ao espaçamento entre fileiras, alguns trabalhos demonstraram a ausência de efeito desse fator sobre a produtividade de grãos, como o conduzido por Heiffig et al. (2006). Por outro lado, Rambo et al. (2003) constataram aumento de produtividade de grãos de soja com a redução do espaçamento de 40 para $20 \mathrm{~cm}$, em decorrência do maior número de vagens férteis por área e maior massa de grãos.

Adicionalmente, nos últimos anos, alguns produtores têm avaliado uma técnica chamada "semeadura cruzada", em que metade das sementes é semeada em um sentido, normalmente o que já vem sendo praticado na lavoura, e a outra metade em sentido transversal, ou seja, cruzando as linhas de semeadura, formando um quadriculado. Todavia, na literatura há poucas informações que indiquem o efeito dessa técnica sobre a produtividade de grãos, bem como sobre a sua interação com a densidade de plantas e o espaçamento entre as fileiras.

O objetivo desse trabalho foi avaliar o desempenho agronômico de cultivares de soja com tipo de crescimento determinado em diferentes arranjos espaciais de plantas, incluindo a semeadura cruzada.

\section{Material e Métodos}

Os experimentos foram realizados na Fazenda Experimental da Embrapa Soja, Londrina, PR, (latitude $23^{0} 11^{\prime}$ Sul, longitude $51^{0} 11^{\prime}$ Oeste e $620 \mathrm{~m}$ de altitude) nas safras 2011/12 e 2012/13. O solo da área experimental foi identificado como Latossolo Vermelho distroférrico (SANTOS et al., 2006) e apresentava os seguintes atributos, na camada de 0 a $20 \mathrm{~cm}$, antes da implantação dos experimentos: 21,4 
$\mathrm{g} \mathrm{dm}^{-3}$ de matéria orgânica; 4,9 de $\mathrm{pH}$ em $\mathrm{CaCl}_{2} ; 8,6$ mg dm ${ }^{-3}$ de P; $0,55 \mathrm{cmol}_{\mathrm{c}} \mathrm{dm}^{-3} \mathrm{de} \mathrm{K} ; 3,7 \mathrm{cmol}_{\mathrm{c}} \mathrm{dm}^{-3}$ de Ca; $1,4 \mathrm{cmol}_{\mathrm{c}} \mathrm{dm}^{-3} \mathrm{de} \mathrm{Mg}$; e $48 \%$ de saturação da CTC por bases.

A aveia-preta (Avena strigosa) presente na área experimental foi manejada mecanicamente aos 11 dias antes da semeadura da soja, utilizando-se um triturador de restos culturais (triton). Nove dias após essa operação, a vegetação remanescente na área foi dessecada quimicamente com glyphosate (1.080 g ha $\left.^{-1}\right)$ e carfentrazone-ethyl (30 $\left.\mathrm{g} \mathrm{ha}^{-1}\right)$.

Nas duas safras, o delineamento experimental foi em blocos completos ao acaso, em esquema fatorial $2 \times 2 \times 2$, com três repetições. Os tratamentos foram formados pela combinação de dois espaçamentos entre fileiras $(0,4$ e $0,6 \mathrm{~m})$, duas densidades de semeadura $(375.000$ e 562.500 sementes ha-1, com germinaçãode $80 \%$ ) e de dois sistemas de semeadura (semeadura cruzada e não cruzada). As parcelas mediam $8,0 \mathrm{~m}$ de comprimento e $4,8 \mathrm{~m}$ de largura, totalizando $38,4 \mathrm{~m}^{2}$. A área utilizada nas avaliações foi de $14,4 \mathrm{~m}^{2}$ (6 $\mathrm{m}$ de comprimento por 2,4 $\mathrm{m}$ de largura).

Na safra 2011/12, utilizou-se a cultivar BRS 294 RR, que possui tipo de crescimento determinado, grupo de maturidade relativa de 6.3 , com semeadura realizada no dia 19/10/2011. Na safra 2012/13, utilizou-se a cultivar BRS $295 \mathrm{RR}$, que possui tipo de crescimento determinado e grupo de maturidade relativa 6.5 , sendo a semeadura realizada em 19/11/12. Em ambas safras a semeadura foi realizada a uma velocidade média de $5 \mathrm{~km} \mathrm{~h}^{-1}$, por meio de uma semeadora-adubadora Marca Semeato, modelo SHM 11/13, equipada com sulcadores do tipo facão guilhotina para o adubo e disco duplo defasado para a semente, e dosadores do tipo disco perfurado com dupla fileira de furos para a semente. As sementes de soja foram tratadas com VitavaxThiran 200SC ${ }^{\circledR}$ (150 mL $50 \mathrm{~kg}^{-1}$ de sementes), Co-Mo Platinum ${ }^{\circledR}$ (100 mL $50 \mathrm{~kg}^{-1}$ de sementes) e inoculante líquido Gelfix $5^{\circledR}\left(100 \mathrm{~mL} 50 \mathrm{~kg}^{-1}\right.$ de sementes). A adubação de base constou da aplicação de $600 \mathrm{~kg} \mathrm{ha}^{-1}$ de superfosfato simples, aplicados a lanço. Em cobertura, foram aplicados $250 \mathrm{~kg}$ $\mathrm{ha}^{-1}$ de cloreto de potássio a lanço, 16 dias após a semeadura. O controle de pragas, doenças e plantas daninhas foi efetuado conforme as indicações técnicas para a cultura. Os dados de precipitação pluvial e temperatura média do ar durante o período entre a semeadura e a colheita estão apresentados na Figura 1.

Durante a fase vegetativa, na safra 2011/12, foram realizadas as seguintes avaliações: massa seca de folhas e ramos por planta e por $\mathrm{m}^{2}$, aos 85 dias após a semeadura (DAS) (R5.1), amostrando-se 10 plantas ao acaso por parcela; e altura de plantas aos 36 (V3), 50 (V5) e 63 DAS (R2), determinada em 15 plantas por parcela.

Na colheita, na safra 2011/12, foram realizadas as seguintes avaliações, amostrando-se 15 plantas por parcela: altura de inserção da primeira vagem; altura de plantas; diâmetro da região do coleto na haste principal; número de nós na haste principal; comprimento médio do internódio; número de ramos por planta; número de ramos por $\mathrm{m}^{2}$; massa seca da haste + ramos + vagens sem grãos por planta e por $\mathrm{m}^{2}$; e índice de colheita aparente, estimado por meio da divisão da massa seca de grãos das 15 plantas amostradas pela massa seca de haste + ramos + vagens sem grãos + grãos.

Também foram avaliados a densidade de plantas, contabilizando-se todas as plantas colhidas na área útil das parcelas, a produtividade de grãos, com padronização da umidade em $13 \%$, e os seguintes componentes do rendimento, amostrando-se 15 plantas por parcela: número de vagens por planta e por $\mathrm{m}^{2}$ provenientes das hastes; número de grãos por planta e por $\mathrm{m}^{2}$ provenientes das hastes; número de grãos por vagem provenientes das hastes; massa de grãos por planta e por $\mathrm{m}^{2}$ provenientes das hastes; massa de mil grãos provenientes das hastes; número de vagens por planta e por $\mathrm{m}^{2}$ provenientes dos ramos; \% de vagens provenientes dos ramos; número de grãos por planta e por $\mathrm{m}^{2}$ provenientes 
dos ramos; \% do número dos grãos provenientes dos ramos; número de grãos por vagem provenientes dos ramos; massa de grãos por planta e por $\mathrm{m}^{2}$ provenientes dos ramos; \% da massa de grãos provenientes dos ramos; e massa de mil grãos provenientes dos ramos. Na safra 2012/13, avaliouse a produtividade de grãos.
Os resultados foram submetidos à análise de variância e teste $\mathrm{F}(p \leq 0,05)$. Para a realização da análise estatística, foi utilizado o programa Sisvar (FERREIRA, 2008).

Figura 1. Precipitação pluvial e temperatura média do ar durante o ciclo de desenvolvimento da cultura da soja, safras 2011/12 e 2012/13. Londrina - PR.

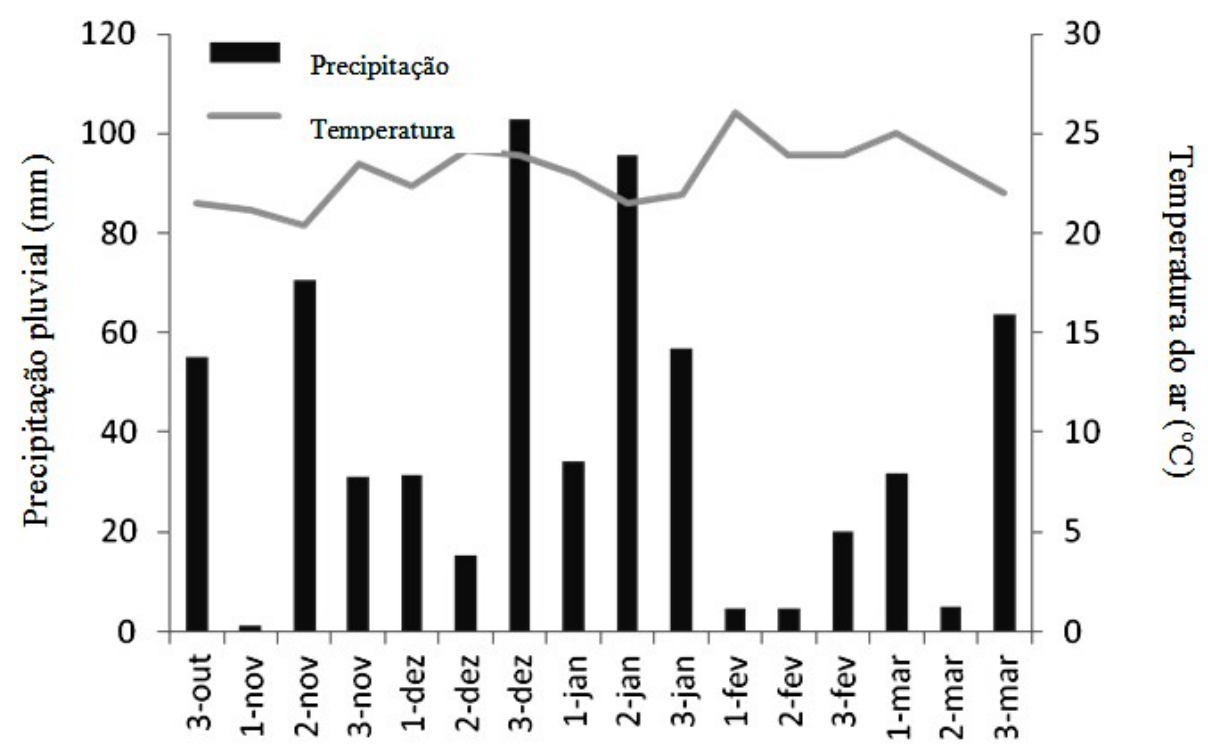

Decêndio-meses. Safra 2011/12

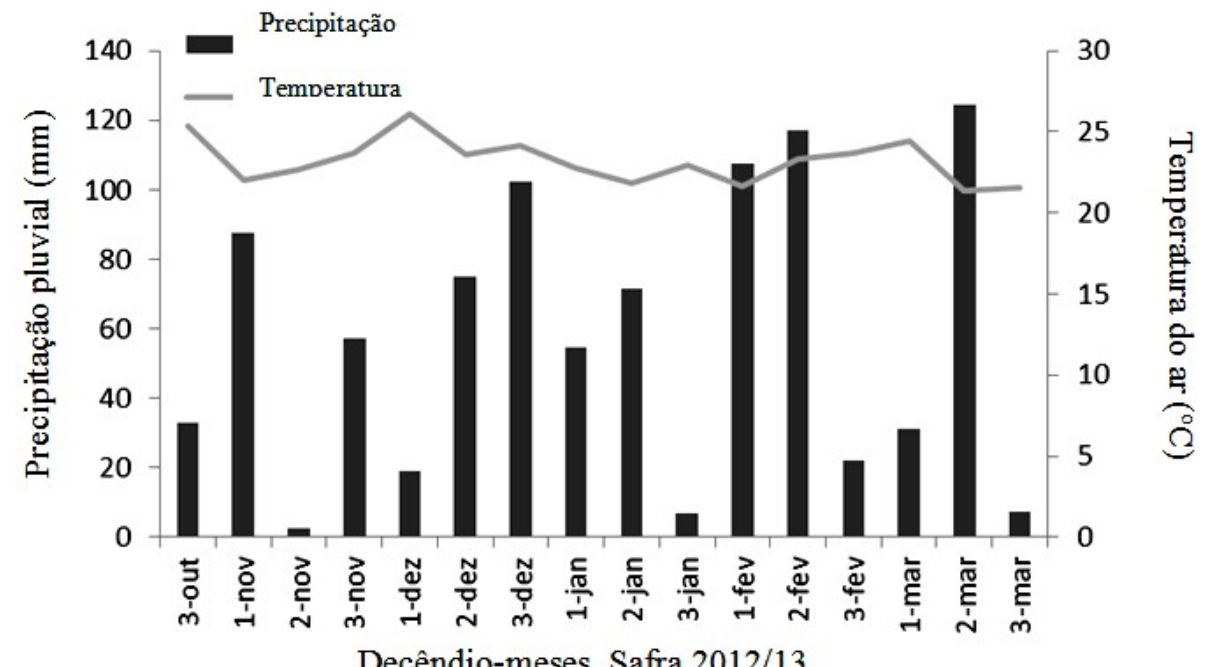

Fonte: Embrapa Soja. Elaboração dos autores. 


\section{Resultados e Discussão}

A massa seca de folhas e ramos por planta ou $\mathrm{m}^{-2}$, avaliada aos $85 \mathrm{DAS}$, não foi influenciada pelo cruzamento ou não das linhas de semeadura. No entanto, houve interação significativa entre os fatores espaçamento e densidade de semeadura para essas variáveis (Tabela 1). Quando se utilizou a densidade de 562,5 mil sementes ha ${ }^{-1}$, não houve efeito entre os espaçamentos para essas variáveis, com exceção da massa seca de folhas $\mathrm{m}^{-2}$, verificando-se que no espaçamento de $0,4 \mathrm{~m}$ entre fileiras houve maior produção de folhas por área. No entanto, com 375 mil sementes ha $^{-1}$, houve maior massa seca de folhas por planta e por $\mathrm{m}^{2} \mathrm{e}$ de ramos por planta no espaçamento de $0,6 \mathrm{~m}$ em relação ao espaçamento de $0,4 \mathrm{~m}$ (Tabela 1). Isso demonstra que, para a cultivar BRS 294 RR, o maior espaçamento entre as fileiras proporcionou melhores condições para o crescimento das plantas na menor densidade de semeadura avaliada.

Tabela 1. Massa seca de folhas e ramos de soja aos 85 dias após a semeadura em diferentes densidades de semeadura e espaçamentos entre fileiras (média dos dois sistemas de semeadura). Londrina, PR, safra 2011/12.

\begin{tabular}{|c|c|c|}
\hline \multirow[t]{3}{*}{ Densidades de semeadura (sementes $\mathrm{ha}^{-1}$ ) } & \multicolumn{2}{|c|}{ Espaçamentos entre fileiras (m) } \\
\hline & 0,4 & 0,6 \\
\hline & \multicolumn{2}{|c|}{ Massa seca de folhas planta ${ }^{-1}(\mathrm{~g})$} \\
\hline 375.000 & $7,23 \mathrm{~b} \mathrm{~A}^{1}$ & 9,49 a $\mathrm{A}$ \\
\hline 562.500 & 5,65 a B & 5,34 a B \\
\hline \multirow[t]{2}{*}{$\mathrm{CV}(\%)$} & & \\
\hline & \multicolumn{2}{|c|}{ Massa seca de folhas $\mathrm{m}^{-2}(\mathrm{~g})$} \\
\hline 375.000 & 196,9 b A & 244,7 a A \\
\hline 562.500 & 226,3 a A & 183,8 b B \\
\hline \multirow[t]{2}{*}{$\mathrm{CV}(\%)$} & \multicolumn{2}{|c|}{14,6} \\
\hline & \multicolumn{2}{|c|}{ Massa seca de ramos planta ${ }^{-1}(\mathrm{~g})$} \\
\hline 375.000 & $12,32 \mathrm{~b} \mathrm{~A}$ & 15,21 a $\mathrm{A}$ \\
\hline 562.500 & 8,96 a B & 8,66 a $\mathrm{B}$ \\
\hline \multirow[t]{2}{*}{$\mathrm{CV}(\%)$} & \multicolumn{2}{|c|}{18,2} \\
\hline & \multicolumn{2}{|c|}{ Massa seca de ramos $\mathrm{m}^{-2}(\mathrm{~g})$} \\
\hline 375.000 & 334,1 a A & 389,9 a $\mathrm{A}$ \\
\hline 562.500 & 357,4 a A & 297,6 a B \\
\hline $\mathrm{CV}(\%)$ & & \\
\hline
\end{tabular}

${ }^{1}$ Médias seguidas pelas mesmas letras, minúsculas nas linhas e maiúsculas nas colunas, não diferem entre si pelo teste $\mathrm{F}$ a $5 \%$ de probabilidade.

Fonte: Elaboração dos autores.

Maior massa seca de folhas e ramos por planta foi observada em densidade de 375 mil sementes $\mathrm{ha}^{-1}$, comparativamente à densidade de 562,5 mil sementes $\mathrm{ha}^{-1}$, nos dois espaçamentos (Tabela 1). No entanto, a massa seca de folhas e ramos por $\mathrm{m}^{2}$ não foi afetada pela densidade de semeadura no espaçamento de 0,4 m. Esse resultado demonstra a alta plasticidade fenotípica que a soja possui, como observado por Gan et al. (2002); Procópio et al. (2013) e Holtz et al. (2014).

A altura de plantas avaliada aos 36 e 63 DAS foi afetada somente pela densidade de semeadura (Tabela 2). Maior densidade de semeadura conferiu altura superior de plantas, possivelmente em razão da menor qualidade de luz presente no dossel. A 
qualidade da luz, percebida pelas plantas por meio dos fotorreceptores, afeta o padrão de crescimento das plantas. Em baixa qualidade da luz, as plantas de soja tendem a exibir alto crescimento em altura, a fim de incrementar a interceptação desse recurso, além de emitir menor quantidade de ramos (BOARD, 2000). No entanto, as diferenças em altura de plantas observadas, apesar de serem significativas estatisticamente, apresentam pouca relevância agronômica. Por outro lado, a altura de plantas aos 50 DAS e na colheita não foi alterada pela densidade de semeadura, pelo espaçamento entre linhas, pelo sistema de semeadura e pela interação entre esses fatores. Isso demonstra que a altura das plantas na cultivar BRS 294 RR é pouco influenciada pelo arranjo espacial das plantas.

Tabela 2. Altura de plantas de soja $(\mathrm{cm})$ em diferentes densidades de semeadura (média dos dois espaçamentos entre fileiras e dos dois sistemas de semeadura). Londrina, PR, safra 2011/12.

\begin{tabular}{lccc}
\hline & \multicolumn{2}{c}{ Densidades de semeadura $\left(\right.$ sementes ha $\left.{ }^{-1}\right)$} & \\
\cline { 2 - 3 } & 375.000 & 562.500 & CV $(\%)$ \\
\cline { 2 - 3 } Altura de plantas aos 36 DAS & $19,4 \mathrm{~b}^{2}$ & $20,7 \mathrm{a}$ & 6,3 \\
Altura de plantas aos 50 DAS & $38,4 \mathrm{a}$ & $37,5 \mathrm{a}$ & 3,3 \\
Altura de plantas aos 63 DAS & $66,4 \mathrm{~b}$ & $69,2 \mathrm{a}$ & 3,2 \\
Altura de plantas na colheita & $73,5 \mathrm{a}$ & $76,2 \mathrm{a}$ & 4,6 \\
\hline
\end{tabular}

${ }^{1} \mathrm{DAS}=$ dias após a semeadura. ${ }^{2}$ Médias seguidas pelas mesmas letras nas linhas não diferem entre si pelo teste $\mathrm{F}$ a $5 \%$ de probabilidade.

Fonte: Elaboração dos autores.

No experimento conduzido na safra 2011/12, com a cultivar BRS $294 \mathrm{RR}$, a produtividade de grãos de soja não foi afetada pela densidade de semeadura, pelo cruzamento ou não das linhas e pela interação entre os fatores investigados. Entretanto, essa variável foi influenciada pelo espaçamento entre as fileiras (Tabela 3). Em espaçamento de 0,6 $\mathrm{m}$, a produtividade foi superior à observada em 0,4 $\mathrm{m}$. É provável que isso tenha ocorrido pela maior penetração de luz no dossel em espaçamento mais amplo, refletindo-se em maior fotossíntese das folhas do terço inferior e maior acúmulo de massa seca por planta (Tabela 1), com reflexos positivos na produtividade. Enfatiza-se que a cultivar BRS 294 RR apresenta alta ramificação e elevada velocidade de fechamento do dossel, fazendo com que as folhas do terço inferior fossem sombreadas precocemente no menor espaçamento. Além disso, o maior espaçamento testado, possivelmente permitiu maior penetração de inseticidas e fungicidas no dossel, proporcionando maior controle de pragas e doenças nas folhas mais próximas ao solo, como discutido por Holtz et al. (2014).

Segundo Ventimiglia et al. (1999), menores espaçamentos propiciam maior quantidade de flores por área, conferindo maior potencial de rendimento, o qual pode ser concretizado em função do genótipo e das condições ambientais, sobretudo disponibilidade de água e nutrientes e regime de temperatura. $\mathrm{Na}$ presente pesquisa, ocorreu pouca precipitação pluvial entre o florescimento e a maturação fisiológica da cultura (Figura 1), contribuindo para o abortamento de flores e abscisão de vagens, o que pode ter ocorrido em maior intensidade no menor espaçamento e na maior densidade de plantas. $\mathrm{O}$ aumento da densidade de plantas de soja pode acentuar as perdas de produtividade de grãos decorrentes do déficit hídrico (WALKER et al., 2010). 
Tabela 3. Produtividade de grãos de soja $\left(\mathrm{kg} \mathrm{ha}^{-1}\right)$ em diferentes espaçamentos entre fileiras, densidades de semeadura e sistemas de semeadura (cruzada e não cruzada). Londrina, PR, safra 2011/12

\begin{tabular}{|c|c|c|}
\hline \multirow{3}{*}{$\begin{array}{c}\text { Densidades de semeadura } \\
\left(\text { sementes } \mathrm{ha}^{-1}\right)\end{array}$} & \multicolumn{2}{|c|}{ Espaçamentos entre fileiras (m) } \\
\hline & 0,4 & 0,6 \\
\hline & \multicolumn{2}{|c|}{ Semeadura cruzada } \\
\hline 375.000 & 3.008 & 3.412 \\
\hline 562.500 & 2.961 & 3.360 \\
\hline \multicolumn{3}{|c|}{ Semeadura não cruzada } \\
\hline 375.000 & 3.167 & 3.425 \\
\hline 562.500 & 3.059 & 3.285 \\
\hline Médias & $3.049 \mathrm{~b}^{1}$ & $3.370 \mathrm{a}$ \\
\hline $\mathrm{CV}(\%)$ & \multicolumn{2}{|c|}{4,6} \\
\hline
\end{tabular}

${ }^{1}$ Médias seguidas pelas mesmas letras nas linhas não diferem entre si pelo teste $\mathrm{F}$ a $5 \%$ de probabilidade.

Fonte: Elaboração dos autores.

No experimento conduzido na safra 2012/13, com a cultivar BRS $295 \mathrm{RR}$, a produtividade de grãos não foi influenciada pelo cruzamento das fileiras, espaçamento e densidade de semeadura, bem como pela interação desses fatores (Tabela 4). Holtz et al. (2014) e Procópio et al. (2013) também verificaram ausência de ganho de produtividade com o uso da semeadura cruzada, comparativamente à não cruzada. Isso demonstra mais uma vez a alta capacidade das cultivares utilizadas em modular o seu crescimento e componentes de rendimento de acordo com as variações no arranjo espacial de plantas na área, mantendo a produtividade por área praticamente constante em uma ampla variação de densidade de plantas, espaçamento entre as fileiras e cruzamento ou não das fileiras.

Tabela 4. Produtividade de grãos de soja $\left(\mathrm{kg} \mathrm{ha}^{-1}\right)$ em diferentes espaçamentos entre fileiras, densidades de semeadura e sistemas de semeadura (cruzada e não cruzada). Londrina, PR, safra 2012/13.

\begin{tabular}{|c|c|c|}
\hline \multirow{3}{*}{$\begin{array}{c}\text { Densidades de semeadura } \\
\left(\text { sementes ha }{ }^{-1}\right)\end{array}$} & \multicolumn{2}{|c|}{ Espaçamentos entre fileiras (m) } \\
\hline & 0,4 & 0,6 \\
\hline & \multicolumn{2}{|c|}{ Semeadura cruzada } \\
\hline 375.000 & $2.507^{\mathrm{ns}}$ & 2.260 \\
\hline 562.500 & 2.182 & 2.161 \\
\hline \multicolumn{3}{|c|}{ Semeadura não cruzada } \\
\hline 375.000 & 2.761 & 2.523 \\
\hline 562.500 & 2.467 & 2.250 \\
\hline $\mathrm{CV}(\%)$ & \multicolumn{2}{|c|}{13,3} \\
\hline
\end{tabular}

${ }^{\text {ns }}$ Diferenças não significativas pelo teste $\mathrm{F}$ a $5 \%$ de probabilidade.

Fonte: Elaboração dos autores. 
Resultados acerca dos efeitos dos espaçamentos entre as fileiras sobre a produtividade da soja são discrepantes. Thomas, Costa e Pires (1998) observaram que, em adequada disponibilidade de nutrientes, houve maior produtividade de grãos de soja em espaçamento entre fileiras de $0,4 \mathrm{~m} \mathrm{em}$ relação a 0,2 m. Por outro lado, Taylor et al. (1982) observaram aumento na produtividade de grãos de soja com a redução do espaçamento de $1,0 \mathrm{~m}$ para 0,25 m, em decorrência da maior interceptação de luz pela cultura, sobretudo no início do ciclo de desenvolvimento, que se refletiu em aumento na produção de massa seca. Por sua vez, Procópio et al. (2013) verificaram que o espaçamento entre fileiras de 0,4 ou 0,6 m não influenciou na produtividade de grãos da soja. Isso demonstra a necessidade de ajuste fitotécnico para cada cultivar, ou pelo menos para cada grupo de cultivares que apresentam características homogêneas de arquitetura de planta, em vários ambientes de produção, como relatado por Gan et al. (2002).
O espaçamento de $0,6 \mathrm{~m}$ permitiu maior ramificação nas plantas de soja (Tabela 5). Nesse espaçamento, os componentes de rendimento relacionados aos ramos, tanto por planta quanto por $\mathrm{m}^{2}$, apresentaram valores superiores aos observados no espaçamento de $0,4 \mathrm{~m}$. A massa de hastes + ramos + vagens sem grãos por planta foi superior no espaçamento de 0,6 m. Isso explica a maior produtividade no espaçamento de $0,6 \mathrm{~m}$ em relação a 0,4 m para a cultivar BRS 294 RR cultivada na safra 2011/12. Frente aos resultados obtidos, verificase que a cultivar BRS 294 RR precisa de maiores espaçamentos para emissão de ramos produtivos. Por outro lado, alguns componentes de rendimento provenientes das hastes, como o número de vagens por $\mathrm{m}^{2}$, o número de grãos por $\mathrm{m}^{2}$ e a massa de grãos foram maiores no espaçamento de $0,4 \mathrm{~m}$ do que em 0,6 m, mas não compensaram a menor produção de grãos nos ramos no espaçamento de $0,4 \mathrm{~m}$.

Tabela 5. Variáveis agronômicas da soja em diferentes espaçamentos entre fileiras (médias de duas densidades e de dois sistemas de semeadura). Londrina, PR, safra 2011/12

\begin{tabular}{|c|c|c|c|}
\hline \multirow[t]{2}{*}{ Variáveis agronômicas } & \multicolumn{2}{|c|}{$\begin{array}{l}\text { Espaçamentos entre fileiras } \\
(\mathrm{m})\end{array}$} & \multirow[t]{2}{*}{$\mathrm{CV}(\%)$} \\
\hline & 0,4 & 0,6 & \\
\hline Número de ramos planta ${ }^{-1}$ & $1,8 \mathrm{~b}^{1}$ & $2,4 \mathrm{a}$ & 18,5 \\
\hline Número de vagens planta ${ }^{-1}$ proveniente de ramos & $11,8 \mathrm{~b}$ & $17,7 \mathrm{a}$ & 22,5 \\
\hline Número de vagens $\mathrm{m}^{-2}$ proveniente de ramos & $370 \mathrm{~b}$ & $495 \mathrm{a}$ & 24,5 \\
\hline Porcentagem de vagens provenientes dos ramos & $27,8 \mathrm{~b}$ & $36,1 \mathrm{a}$ & 15,3 \\
\hline Número de grãos planta ${ }^{-1}$ provenientes de ramos & $18,7 \mathrm{~b}$ & 26,4 a & 25,3 \\
\hline Número de grãos $\mathrm{m}^{-2}$ provenientes de ramos & $578 \mathrm{~b}$ & $750 \mathrm{a}$ & 27,6 \\
\hline Porcentagem de grãos provenientes de ramos & $26,6 \mathrm{~b}$ & $35,1 \mathrm{a}$ & 16,5 \\
\hline Massa de grãos provenientes de ramos (g planta $\left.{ }^{-1}\right)$ & $3,36 \mathrm{~b}$ & $4,84 \mathrm{a}$ & 24,8 \\
\hline Massa de grãos provenientes de ramos $\left(\mathrm{g} \mathrm{m}^{-2}\right)$ & $104,6 \mathrm{~b}$ & $137,1 \mathrm{a}$ & 28,0 \\
\hline Porcentagem da massa de grãos provenientes de ramos & $26,3 \mathrm{~b}$ & $34,3 \mathrm{a}$ & 17,0 \\
\hline Número de vagens $\mathrm{m}^{-2}$ proveniente de hastes & $969 \mathrm{a}$ & $859 \mathrm{~b}$ & 8,1 \\
\hline Número de grãos $\mathrm{m}^{-2}$ provenientes de hastes & $1604 \mathrm{a}$ & $1348 \mathrm{~b}$ & 12,1 \\
\hline Massa de grãos provenientes de hastes $\left(\mathrm{g} \mathrm{m}^{-2}\right)$ & $294 \mathrm{a}$ & $254 \mathrm{~b}$ & 11,3 \\
\hline $\begin{array}{l}\text { Massa de hastes }+ \text { ramos }+ \text { vagens sem grãos } \\
\left(\text { g planta }^{-1}\right)\end{array}$ & $13,0 \mathrm{~b}$ & $14,7 \mathrm{a}$ & 9,3 \\
\hline
\end{tabular}

${ }^{1}$ Médias seguidas pelas mesmas letras nas linhas não diferem entre si pelo teste $\mathrm{F}$ a $5 \%$ de probabilidade.

Fonte: Elaboração dos autores. 
A maior densidade de semeadura, 562,5 mil sementes $\mathrm{ha}^{-1}$, conferiu maior altura de inserção da primeira vagem e maior comprimento do entre nó em relação à densidade de 375 mil sementes ha ${ }^{-1}$ (Tabela 6), corroborando com os dados de altura de plantas (Tabela 2). Entretanto, o aumento de 1,5 $\mathrm{cm}$ na altura de inserção da primeira vagem possui pouca importância agronômica. $\mathrm{O}$ aumento da quantidade de plantas por área também reduziu o diâmetro do caule e do número de ramos por planta (Tabela 6), em virtude do aumento da competição por água, luz e nutrientes entre as plantas de soja. Esse padrão de mudança morfológica da soja frente ao aumento da densidade de plantas também foi contatado por Martins et al. (1999) e por Procópio et al. (2013).

A semeadura cruzada afetou significativamente a densidade de plantas na colheita da soja (Tabela 7). Com o cruzamento das linhas, houve redução da densidade de plantas, pois a segunda operação de semeadura, transversal à primeira, prejudicou a qualidade da primeira operação em virtude do revolvimento do solo ocasionado pela segunda passagem da semeadora e da compactação adicional imposta pelo rodado do trator e da semeadora. $\mathrm{Na}$ prática essa é uma informação relevante, já que para se ter a mesma densidade de plantas por hectare no sistema de semeadura cruzada há necessidade de maior gasto de sementes, em relação à semeadura sem cruzamento das linhas. Possivelmente em função da redução da densidade de plantas ocasionada pela semeadura cruzada, houve maior número de ramos por planta com o cruzamento das linhas, menor número de vagens e grãos por $\mathrm{m}^{2} \mathrm{e}$ menor massa de hastes + ramos + vagens sem grãos por $\mathrm{m}^{2} \mathrm{em}$ relação à semeadura não cruzada. Todavia, a semeadura cruzada não alterou a produtividade de grãos (Tabelas 3 e 4), demonstrando que, na presente condição experimental, essa não é uma tecnologia que pode aumentar expressivamente a produtividade da cultura.

Tabela 6. Variáveis agronômicas da soja em diferentes densidades de semeadura (médias de dois espaçamentos entre fileiras e de dois sistemas de semeadura ). Londrina, PR, safra 2011/12.

\begin{tabular}{lccc}
\hline \multicolumn{1}{c}{ Variáveis agronômicas } & \multicolumn{2}{c}{$\begin{array}{c}\text { Densidade de semeadura } \\
\left(\text { sementes ha }^{-1}\right)\end{array}$} & CV(\%) \\
\hline & 375.000 & 562.500 & \\
Altura de inserção da primeira vagem (cm) & $11,5 \mathrm{~b}$ & $13,0 \mathrm{a}$ & 12,1 \\
Diâmetro do caule na região do colo (mm) & $6,9 \mathrm{a}$ & $6,2 \mathrm{~b}$ & 4,3 \\
Comprimento do internódio $(\mathrm{cm})_{\text {Número de ramos planta }^{-1}}^{5,20 \mathrm{~b}}$ & $5,43 \mathrm{a}$ & 3,5 \\
Número de ramos m $^{-2}$ & $2,47 \mathrm{a}$ & $1,68 \mathrm{~b}$ & 18,5 \\
\hline
\end{tabular}

${ }^{1}$ Médias seguidas pelas mesmas letras nas linhas não diferem entre si pelo teste $\mathrm{F}$ a $5 \%$ de probabilidade.

Fonte: Elaboração dos autores.

Tabela 7. Variáveis agronômicas da soja em diferentes sistemas de semeadura (médias de dois espaçamentos entre fileiras e duas densidades de semeadura). Londrina, PR, safra 2011/12.

\begin{tabular}{|c|c|c|c|}
\hline \multirow[t]{2}{*}{ Variáveis agronômicas } & \multicolumn{2}{|c|}{ Sistema de semeadura } & \multirow[t]{2}{*}{$\mathrm{CV}(\%)$} \\
\hline & Cruzado & Não Cruzado & \\
\hline Densidade de plantas na colheita $\left(\mathrm{mil} \mathrm{ha}^{-1}\right)$ & $284 b^{1}$ & $355 \mathrm{a}$ & 7,9 \\
\hline Número de ramos planta ${ }^{-1}$ & $2,28 \mathrm{a}$ & $1,87 \mathrm{~b}$ & 18,5 \\
\hline Número de vagens proveniente de hastes $\mathrm{m}^{-2}$ & $822 \mathrm{~b}$ & $1005 \mathrm{a}$ & 8,1 \\
\hline Número de grãos $\mathrm{m}^{-2}$ provenientes de hastes & $1313 \mathrm{~b}$ & $1638 \mathrm{a}$ & 12,1 \\
\hline Massa de grãos provenientes de hastes $\left(\mathrm{g} \mathrm{m}^{-2}\right)$ & $240,5 \mathrm{~b}$ & 308,4 a & 11,3 \\
\hline Massa de hastes + ramos + vagens sem grãos $\left(\mathrm{g} \mathrm{m}^{-2}\right)$ & $391,7 \mathrm{~b}$ & 467,2 a & 12,3 \\
\hline
\end{tabular}

${ }^{1}$ Médias seguidas pelas mesmas letras nas linhas não diferem entre si pelo teste $\mathrm{F}$ a $5 \%$ de probabilidade.

Fonte: Elaboração dos autores. 
As variáveis número de nós na haste principal (média=14,1 e CV=3,2\%); índice de colheita aparente (média $=0,48$ e CV=2,9\%); número de grãos por vagem proveniente das hastes (média=1,62 e $\mathrm{CV}=8,3 \%$ ) e dos ramos (média $=1,53$ e $\mathrm{CV}=8,2$ ); e a massa de mil grãos provenientes das hastes (média $=186 \mathrm{~g}$ e CV=4,9\%) e dos ramos (média=181g e $\mathrm{CV}=4,6 \%$ ) não foram afetadas pelos tratamentos. Isso demonstra que, para a cultivar BRS 294 RR, os arranjos espaciais de plantas, embora discrepantes, pouco afetaram essas variáveis, que são relevantes na determinação da produtividade de grãos.

\section{Conclusões}

A produtividade de grãos não foi influenciada pelo cruzamento ou não das fileiras, pela densidade de plantas e pela interação entre esses fatores, o que demonstra a alta plasticidade fenotípica das cultivares utilizadas.

Para a cultivar BRS 294 RR, o espaçamento de $0,6 \mathrm{~m}$ entre as fileiras conferiu maior produtividade de grãos em relação ao espaçamento de $0,4 \mathrm{~m}$, principalmente porque proporcionou aumento da produção de grãos oriunda dos ramos.

\section{Agradecimentos}

Ao CNPq pela concessão de bolsa de Produtividade em Desenvolvimento Tecnológico e Extensão Inovadora ao primeiro autor e bolsa de Produtividade em Pesquisa ao segundo autor.

\section{Referências}

BOARD, J. Light interception efficiency and light quality affect yield compensation of soybean at low plant population. Crop Science, Madison, v. 40, n. 5, p. 12851294, 2000.

BRUIN, J. L.; PEDERSEN, P. Effect of row spacing and seeding rate on soybean yield. Agronomy Journal, Madison, v. 100, n. 3, p. 704-710, 2008.

COOPERATIVE EXTENSION SERVICE AMES. How a soybean plant develops. Ames: Iowa State University of Science and Technology, 1994. 20 p.

COX, W. J.; CHERNEY, J. H. Growth and yield responses of soybean to row spacing and seeding rate. Agronomy Journal, Madison, v. 103, n. 1, p. 123-128, 2011.

COX, W. J.; CHERNEY, J. H.; SHIELDS, E. Soybeans compensate at low seeding rate but not at high thinning rates. Agronomy Journal, Madison, v. 102, n. 4, p. 12381243, 2010.

FERREIRA, D. F. SISVAR: um programa para análises e ensino de estatística. Revista Symposium, Lavras, v. 6, n. 2, p. 36-41, 2008.

GAN, Y.; STULEN, I.; VAN KEULEN, H.; KUIPER, P. J. C. Physiological response of soybean to plant density. Field Crops Research, Amsterdam, v. 74, n. 2-3, p. 231241, 2002.

HANNA, S.; CONLEY, S. P.; SHANER, G. E.; SANTINI, J. B. Fungicide application timing and row spacing effect on soybean canopy penetration and grain yield. Agronomy Journal, Madison, v. 100, n. 5, p. 14881492, 2008.

HEIFFIG, L. S.; CÂMARA, G. M. S.; MARQUES, L. A.; PEDROSO, D. B.; PIEDADE, S. M. S. Fechamento e índice de área foliar da cultura da soja em diferentes arranjos espaciais. Bragantia, Campinas, v. 65 , n. 2, p. 285-295, 2006.

HOLTZ, V.; COUTO, R. F.; OLIVEIRA, D. G.; REIS, E. F. Deposição de calda de pulverização e produtividade da soja cultivada em diferentes arranjos espaciais. Ciência Rural, Santa Maria, v. 44, n. 8, p. 1371-1376, 2014.

LIMA, S. F.; ALVAREZ, R. C. F.; THEODORO, G. F.; BAVARESCO, M.; SILVA, K. S. Efeito da semeadura em linhas cruzadas sobre a produtividade de grãos e severidade da ferrugem asiática da soja. Bioscience Journal, Uberlândia, v. 28, n. 6, p. 954-962, 2012.

MARTINS, M. C.; CÂMARA, G. M. S.; PEIXOTO, C. P.; MARCHIORI, L. F. S.; LEONADO, V.; MATTIAZZI, P. Época de semeadura, densidade de plantas e desempenho vegetativo de cultivares de soja. Scientia Agricola, Piracicaba, v. 56, n. 4, p. 851-858, 1999.

PIRES, J. L.; COSTA, J. A.; THOMAS, A. L. Rendimento de grãos de soja influenciado pelo arranjo de plantas e níveis de adubação. Pesquisa Agropecuária Gaúcha, Porto Alegre, v. 24, n. 2, p. 183-188, 1998.

PROCÓPIO, S. O.; BALBINOT JUNIOR, A. A.; DEBIASI, H.; FRANCHINI, J. C.; PANISON, F. Plantio cruzado na cultura da soja utilizando uma cultivar de hábito de crescimento indeterminado. Revista de Ciências Agrárias, Belém, v. 56, n. 4, p. 319-325, 2013. 
. Estimativa do potencial de rendimento por estrato do dossel da soja, em diferentes arranjos de plantas. Ciência Rural, Santa Maria, v. 34, n. 1, p. 33-40, 2004.

RAMBO, L.; COSTA, J. A.; PIRES, J. L. F.; PARCIANELLO, G.; FERREIRA, F. G. Rendimento de grãos da soja em função do arranjo de plantas. Ciência Rural, Santa Maria, v. 33, n. 3, p. 405-411, 2003.

SANTOS, H. G. dos; JACOMINE, P. K. T.; ANJOS, L. H. C. dos; OLIVEIRA, V. A. de; OLIVEIRA, J. B. de; COELHO, M. R.; LUMBRERAS, J. F.; CUNHA, T. J. F. (Ed.). Sistema brasileiro de classificação de solos. 2. ed. Rio de Janeiro: Embrapa Solos, 2006. 306 p.

SHAW, R. H.; WEBER, C. R. Effects of canopy arrangements on light interception and yield of soybeans. Agronomy Journal, Madison, v. 59, n. 2, p. 155-159, 1967.

TAYLOR, H. M.; MASON, W. K.; BENNIE, A. T. P.; ROWSE, H. R. Responses of soybeans to row spacings and two soil water levels. I. An analysis of biomass accumulation, canopy development, solar radiation interception and components of seed yield. Field Crops Research, Amsterdam, v. 5, n. 1, p. 1-14, 1982.
THOMAS, A. L.; COSTA, J. A.; PIRES, J. L. Rendimento de grãos de soja afetado pelo espaçamento entre linhas e fertilidade do solo. Ciência Rural, Santa Maria, v. 28, n. 4, p. 543-546, 1998.

TOURINO, M. C. C.; REZENDE, P. M.; SALVADOR, N. Espaçamento, densidade e uniformidade de semeadura na produtividade e características agronômicas da soja. Pesquisa Agropecuária Brasileira, Brasília, v. 37, n. 8, p. 1071-1077, 2002.

VENTIMIGLIA, L. A.; COSTA, J. A.; THOMAS, A. L.; PIRES, J. L. F. Potencial de rendimento da soja em razão da disponibilidade de fósforo no solo e dos espaçamentos. Pesquisa Agropecuária Brasileira, Brasília, v. 34, n. 2, p. 195-199, 1999.

WALKER, E. R.; MENGISTU, A.; BELLALOUI, N.; KOGER, C. H.; ROBERTS, R. K.; LARSON, J. A. Plant population and row-spacing effects on maturity group III soybean. Agronomy Journal, Madison, v. 102, n. 3, p. 821-826, 2010. 
